\title{
ASO Visual Abstract: Objective Assessment of Postoperative Morbidity Following Breast Cancer Treatments with Wearable Activity Monitors: The "BRACELET" Study
}

\author{
Nur Amalina Che Bakri, MBChB, BMedSc, MPhil ${ }^{1,2}$ (D), Richard M. Kwasnicki, PhD, MRCS ${ }^{1,2}$, \\ Kieran Dhillon, BSc ${ }^{1}$, Naairah Khan, BSc ${ }^{1}$, Omar Ghandour, BSc ${ }^{1}$, Alexander Cairns, MBBS ${ }^{2}$, \\ Ara Darzi, FRCS, FRS ${ }^{1,2}$, and Daniel R. Leff, PhD, MS (Hons), FRCS ${ }^{1,2}$ \\ ${ }^{1}$ Department of Surgery and Cancer, Imperial College London, London, UK; ${ }^{2}$ Academic Surgical Unit, St. Mary's \\ Hospital, Imperial College Healthcare NHS Trust, London, UK
}

Upper limb functionality after breast and axillary surgery lacks quantitative morbidity measurement. Wearable activity monitors (WAMs) provide objective insights into upper limb function which may enable characterization of recovery of breast oncoplastic procedures and aid in the development of personalized rehabilitation (https://doi.org/ 10.1245/s10434-021-10458-4).

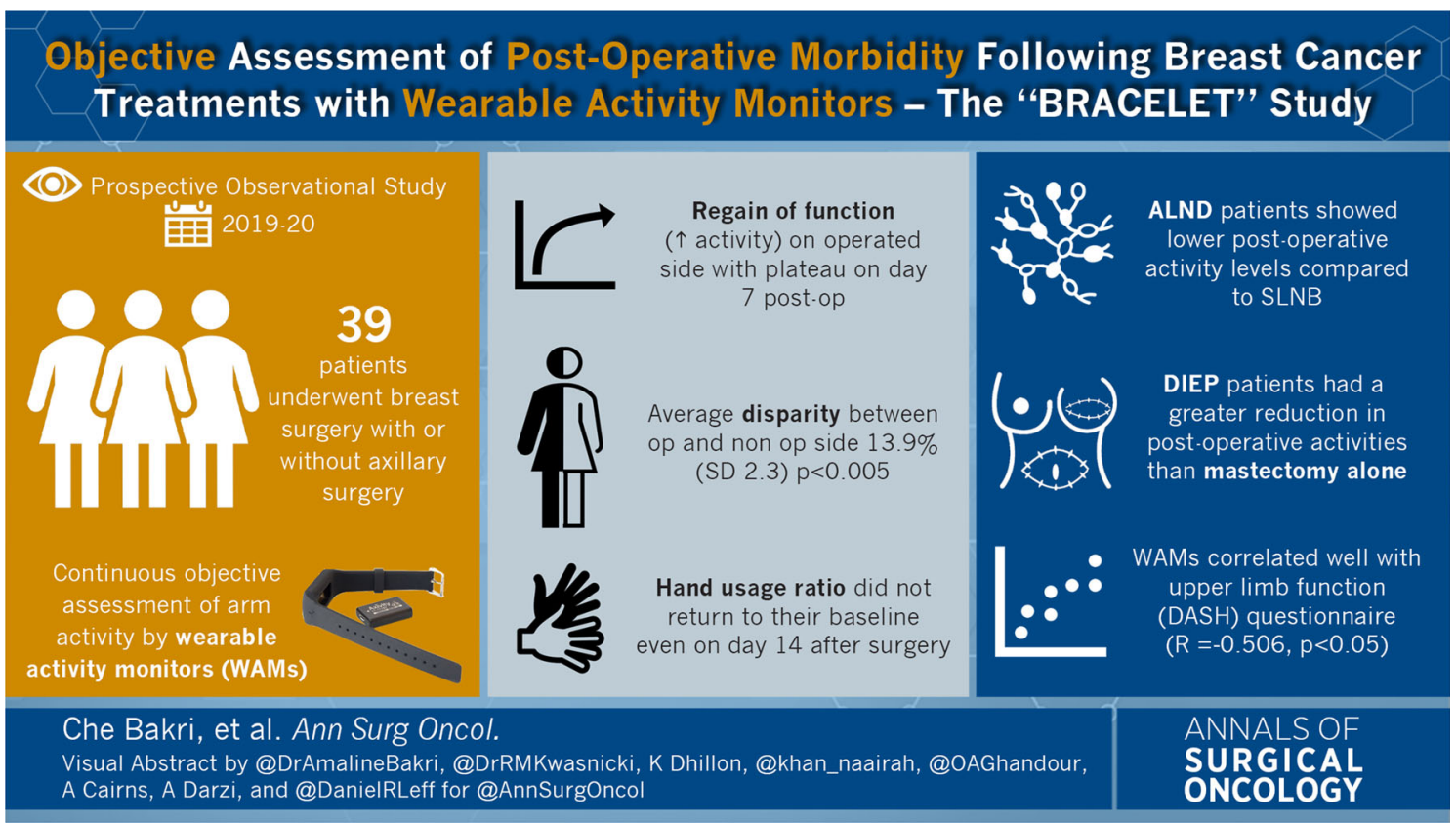

(C) Crown 2021

FUNDING National Institute for Health Research (NIHR) Imperial Biomedical Research Centre (BRC). Award number: WSSS_P69945

DISCLOURES The authors declare that they have no conflict of interest.

Published Online: 9 September 2021

N. A. Che Bakri, MBChB, BMedSc, MPhil

e-mail: nchebakr@ic.ac.uk
Publisher's Note Springer Nature remains neutral with regard to jurisdictional claims in published maps and institutional affiliations. 